\title{
Between Choice and Obligation: An Exploratory Assessment of Forced Marriage Problems and Policies among Migrants in the United States
}

\author{
Anthony Marcus*, Popy Begum**, Laila Alsabahi*** and Ric Curtis ${ }^{\dagger}$ \\ * Department of Anthropology, John Jay College of the Criminal Justice, City University of New York \\ E-mail: amarcus@jjay.cuny.edu \\ ** School of Criminal Justice, Rutgers University-Newark \\ E-mail: popy.begum@rutgers.edu \\ ***Research and Evaluation Center, John Jay College of Criminal Justice, City University of New York \\ E-mail: lalsabahi@jjay.cuny.edu \\ ${ }^{\dagger}$ Department of Anthropology, John Jay College of the Criminal Justice, City University of New York \\ E-mail: rcurtis@jjay.cuny.edu
}

Recently, in the United States (US) there has been increasing interest in and advocacy for developing research and policies that identify and address what has, in the European context, been called child and forced marriage, in which migrant parents, typically from the Middle East, North Africa and South Asia (MENASA) impose marital choices on their Western-raised children, through coercion, psychological pressure, or the threat of violence. Despite widespread international concern, there remains little research-based empirical knowledge about the problem in the United States. Drawing on interviews with 100 City University of New York students from MENASA families, this study documents significant intergenerational conflict over honour, sexuality, and marital choice and suggests a high likelihood that coercive marital situations are present in the US. However, the different socio-political environment encountered by migrant families in the US may not effectively accommodate European style anti-forced marriage policy constructions and criminal justice responses.

Keywords: Forced marriage, family honour, immigrant adaptation, family conflict, interculturality.

\section{Introduction}

During the past decade, European parliaments, researchers, and social service providers have recognised forced marriages, in which migrant parents impose marital choices on their European-raised children through coercion, emotional abuse, psychological pressure, kidnapping, trickery, physical violence, or the threat of violence, as an important concern (Anitha and Gill, 2009). Denmark, Germany, Austria, Belgium, Turkey, the United Kingdom (UK), and the Netherlands have developed social service and law enforcement structures to address this problem, which is generally viewed as primarily affecting migrants from the Middle East, North Africa, and South Asia (henceforth MENASA). Additionally, some MENASA sending countries have begun discussions with European governments about their role in non-consensual marriage (Chantler et al., 2009). 
In the United States (US), which is home to over three million migrants from MENASA countries (United States Census, 2010), a small movement of activists and academics has advocated for European-style policies that explicitly identify, research, and address forced marriages and the related phenomena of child marriage typically parental arrangement of marriages for fifteen, sixteen and seventeen year olds) and honour violence (often involving familial conflict over marriage and dating). The US Congress issued a 201314 committee paper entitled, 'Violence against Women: Prevention and Prosecution Programs' that mentioned honour violence (US House of Representatives, 2014) and commissioned a still unpublished report on honour violence, methodologies for studying it, and how to measure its prevalence in the US (personal communication with researcher).

US politicians have also engaged the problem of child and forced marriage, including former US Secretary of State Hillary Clinton who publicly demanded new policies (see for instance Clinton, 2011) and former president Barack Obama who described child marriage as 'a threat to fundamental human rights' (Girlsnotbrides, 2013). While such efforts have been largely directed towards the occurrence of child and forced marriage in developing nations (see for instance Sikder, 2013), it is an issue that has also appeared in domestic discussions.

The US media has also raised the issue (see Bennhold, 2013; and Robbins, 2009) and non-profit organisations that address gender-based violence and trafficking have sponsored educational conferences for law enforcement officials, social service providers, and the general public. Notably, the John F. Kennedy School of Government at Harvard University has hosted a web-based publication that argues that forced marriage is a serious and widespread problem in the US that should be addressed using policy tools developed in Europe. Leading this effort nationally is the AHA Foundation, founded by the Dutch feminist Ayaan Hirsi Ali in 2007, which has hosted three national conferences at John Jay College of Criminal Justice between 2011 and 2013 that targeted 'police officers, $\mathrm{FBI}$ agents, prosecutors, judges, social workers, domestic violence advocates, guidance counselors, and representatives from numerous other NGOs' (AHA, 2014), and has a record of extensive lobbying for European style laws and policies.

Several other organisations have taken up this issue. In 2007 the Global Justice Initiative, founded by Julia Alanen, also from the Netherlands, advocated for Europeanstyle forced marriage laws and institutions. The Tahirih Justice Center, an organisation of pro bono attorneys providing legal services and national public policy advocacy for immigrant women who are victims of gender-based violence added a forced marriage component to their work at roughly the same time.

In addition, there is a developing network of service organisations that is also part of this effort. The Polaris Project, a national anti-trafficking organisation, has developed advocacy and a hotline around the issue of forced marriage, and many local and regional civil society organisations working with migrant women in victims' services, family counselling, and gender based violence have similarly taken up the issue. Sauti Yetu, which provides such services for migrant African women and Manavi, which has a similar mission for South-Asian women in the US, are probably the two most prominent examples.

These organisations have argued for European-style forced marriage laws and public institutions; in particular, they cite the example of the UK's Forced Marriage Unit. However, with the exception of Begum (2016), there has been little research that attempted to assess the prevalence and nature of forced marriage in the US or the potential efficacy of 
importing such European style criminal justice oriented policy instruments for vulnerable individuals in the US.

In the following paper, we address this lacuna by developing an exploratory assessment of the problem of parental marriage arrangement for minors and intergenerational conflict over dating, sexuality and marital choice among MENASA youth in the US. Drawing on interviews with a purposive sample of 100 young Americans whose families originate in the countries identified, in the European context, as being most likely to produce child or non-consensual marriages, this article presents a preliminary view of the family conflicts and cultural values upon which child and forced marriage definitions and policies have been created in Europe, and are now being proposed in the US.

Respondents were recruited through random intercept at campuses across the City University of New York (CUNY) in 2012. This sample was chosen for accessibility, age range, and the expectation that coercive marital situations are likely to be less prevalent among individuals enrolled in tertiary education than similarly aged individuals who are not. This, it was hypothesised, is due to the role a university education has historically played in integrating migrants and giving them a greater range of life choices (Sarroub, 2001; Qin, 2006).

Findings show significant and widespread intra-familial conflict over dating, marital choice, and sexuality within the immediate families and social networks of CUNY students of MENASA descent. This suggests that non-consensual marriage may be problematic for some young people in migrant communities in the US. However, we hypothesise that European legal definitions and policy constructions of forced marriage may not be the most suitable for addressing such situations in the US context where the web of obligations and entitlements between the state and individual citizens is less developed and the citizenship of adults in their early twenties is typically mediated through natal families, in the form of parental tax incentives and employment-based health insurance that identify adult children as 'dependants'; and most crucially, need based financial aid for tertiary education that is based on parental income.

\section{Contemporary knowledge on 'forced marriage'}

Discussions of free-choice, arranged, child, and forced marriages are complex. The popular depiction of a 'Western' marriage is one that is based on love, individual choice, self-actualisation, and mutual consent. Non-western marriages are often characterised as arranged, the purpose of which is to respect traditions and strengthen family economy and kinship networks (e.g. Epstein et al., 2013; Smart and Shipman, 2004). Smart and Shipman (2004), however, argue that marriage decisions occur on 'a continuum along which degrees of attentiveness to kinship structures and parental wishes fluctuate' (p. 495). Many individual choices actually involve negotiations between family members over who is an acceptable partner, and many arranged marriages often contain significant elements of individual choice.

Related to this are child marriages (typically defined as marriage before the age of eighteen), which are often conflated with forced marriages because of questions concerning consent (Chantler, 2012). Although not all child marriages are viewed as forced, consent is generally viewed as compromised when a marriage is arranged for a child who is very young and blurred when a sixteen or seventeen-year-old child marries 
(Chantler, 2012). Thus, central to legal approaches to 'forced marriage' is the distinction between consensual and non-consensual 'arranged marriages'. ${ }^{1}$

The US Department of State (2005: 9) provides definitions of arranged and forced marriages that have been widely used internationally:

In arranged marriages, the families of both spouses take a leading role in arranging the marriage but the choice whether to accept the arrangement remains with the individuals. In a forced marriage, at least one party does not consent or is unable to give informed consent to the marriage, and some element of duress is generally present.

Although arranged marriages and forced marriages occur in many nations and cultures, including advanced industrial democracies (Baer, 1988; Xiaohe and Whyte, 1990; Yost, 1994; Balán, 1996; Foner, 1997; Goluboff, 2001; Mair, 2013; Wierucka, 2013), both are most associated with MENASA countries (e.g. Oprea, 2005; Chantler et al., 2009; Forced Marriage Unit, 2014). This labelling of certain practices and crimes as being cultural in nature has sparked numerous discussions about stigmatising migrant cultural practices and its outcome on forced marriage, conceptions of honour, and kinship relations (e.g. Shalhoub-Kevorkian, 2004; Wilson 2007; Ahmetbeyzade, 2008; Abu-Lughod, 2011).

Scholarly literature in the UK has focused heavily on the problems of such stigmatising of migrant customs, with questions about the role of multiculturalism and migration law in facilitating or even encouraging forced marriage (Hester et al., 2007; Chantler et al., 2009). Similarly, the politics of race and ethnocentrism have been identified as inscribed in the idea of forced marriage (Volpp, 2000; Phillips and Dustin, 2004; Razak, 2004; Oprea, 2005; Gill and Anitha, 2011). Scholars rejecting ethnocentrism have referenced divisions over values around marriage within migrant communities (Caroll, 1998; Gangoli et al., 2006) and state level migration policies, especially residence rules for spouses of citizens (Hossain and Turner, 2002; Phillips and Dustin, 2004; Wilson, 2007). In this way, much of the discussion has focused on whether forced marriage is a problem derived from the culture of the sending country or the legal framework, political economy, and social dynamics of the receiving country. Central to this discussion have been concerns about the impact of post September 11, 2001 Islamophobia and the focus on Muslim populations in Europe (Wilson, 2007).

According to most research, arranged marriages occur throughout the world and vary from highly coercive to entirely consensual (Home Office, 2000). Newspapers in many MENASA countries run classified advertisements by parents acting as marriage brokers for adult sons and daughters, many of whom are successful professionals. In parts of the world where peasant agrarian corporate families predominate, dating typically does not exist, and the ideal of a companionate 'love' union remains uncommon; children in these communities rarely have or expect the final decision in their marriage (Jejeebhoy and Sathar, 2001; Ghimire et al., 2006; Jacoby and Mansuri, 2010).

When families from 'traditional' backgrounds migrate to nearby cities or to Western nations, a clash of values may emerge. Children raised in the receiving society may expect to exclude parents from the choice of a spouse or request that parents broker the arrangement, rather than have the parents make the final decision. At the same time, parents, often isolated in nuclear families in receiving countries, may seek a more traditional path. The resulting incompatible expectations of parents and children can lead 
to tensions. In situations where there is direct conflict between the desires of the parents and those of the children, 'forced marriage' sometimes occurs (Home Office, 2000).

Nearly all studies of forced marriage to date have been in Europe, where it is a widely accepted concern and countries have enacted laws to address the problem (Hvilshøj, 2006; Stollavistskaia and McElroy, 2005). The UK has probably had the most robust response from both a policy and scholarship perspective. The Forced Marriage Unit, founded in 2006 by an act of Parliament, reports that 'advice or support' was given in 1,485 cases involving individuals from sixty sending countries between 2007 and 2013. It has published reports on forced marriage in the UK, surveyed police records, and attempted to identify numbers and trends (Foreign and Commonwealth Office et al., 2006; Foreign and Commonwealth Office and Home Office, 2013).

By contrast, in the US there has been little empirical research. Critical theorists have addressed macro-political issues related to post-9/11 invidious representations of Muslim women (Siddiqi, 2005; Abu-Lughod, 2011; Toor, 2012). However, the few empirical analyses of the problem have been adjunct to social service interventions or campaigns to introduce European definitions and policy frameworks.

Alanen (2011) compiled a record of the laws and statutes related to marriage and consent across the US for the Global Justice Initiative. Tahirih Justice Center (2011) found 'as many as 3,000 known and suspected cases' (p.2) in a web-based survey of organisations and agencies in the US 'that may have encountered forced marriage cases' (p. 4). Roy (2011) produced a report on the contours of forced marriage for Manavi, an organisation for South Asian woman. The report provides extensive descriptions of forced marriage in the United States, but these descriptions depend on what the author refers to as 'composite case studies' (p.19), offering in an endnote that 'the following are not real cases' (Roy, 2011: 52).

Sri and Raja's study (2013) represents the largest data set to date. They surveyed 524 South Asian students, domestic violence professionals, and refugee service providers at the end of a day of participation in voluntary (for the students) and mandatory (for the professionals) seminars and professional talks at an event held by Gangashakti (an antiforced marriage organisation) to raise consciousness about the problem in the United States. They conclude, based on the post-training assessment, that 'the practice of forced marriage does impact a wide variety of communities in the United States' (Sri and Raja, 2013: 38).

The Sauti Yetu Center for African Women (2012) study probably provides the richest empirical examination of forced marriage as an issue in the United States. Drawing on focus groups and interviews of thirty young women in their support programs for African migrant women in NYC and textual analysis of past case studies in which interrupted schooling was an issue in the lives of their served population, this report provides a rich picture of the struggles over dating, marital choice, education, and personal agency confronted by young African woman in New York City. While they begin by arguing for the US to follow 'other industrialized countries in their efforts to prevent early and forced marriage' (p.1), their overall focus is not toward legal sanctions against embedded cultural traditions, but rather on the difficult interstitial social environment and dearth of institutional/citizenship support within which migrant family life is created and given meaning. Our study seeks to continue these themes and questions raised by Sauti Yetu with a larger broader sample and research questions and methods that are separated from the imperatives of specific programing around forced marriage. 


\section{Methodology}

Reduced marital choice has been reported as resulting from actions ranging from subtle emotional pressures not to disappoint parents or other family members, to parents taking their children on a family vacation to the sending country and forcing them to marry while there (Zaidi and Shuraydi, 2002; Twamley, 2013). The present study sought to understand how respondents experience this continuum by developing an interview instrument that used neutral and open-ended questions that would capture the life experiences and values of our respondents without compelling judgments about whether marriages in their social networks were forced.

Data collection began in June 2012 and continued until May 2013, consistent with the one year approval of research granted to the project principal investigators by the City University of New York Institutional Review Board ethics audit. One hundred university students with at least one parent from the MENASA region were interviewed at the City University of New York (fifty-nine female, forty-one male). Similar to Hester et al. (2007), students from MENASA migrant families were targeted in order to develop a comparison with contemporary European research which identifies forced marriage as most prevalent among seventeen to twenty-five year olds in MENASA migrant communities (see Foreign and Commonwealth Office and Home Office, 2013). Additionally, our goal was to develop an understanding of the consciousness of a generation that has grown up in New York in the context of migrant culture. University students were chosen for reasons of accessibility and the hypothesis that 'forced marriage' would be least prevalent among young adults with the significant social and cultural capital and class privileges that are afforded those who go to university. Findings of reduced choice and increased family pressure around marital choice within this relatively privileged, geographically mobile, and socially outward looking group would be more significant than a random sample in a specific community.

Recruitment was accomplished through intercept at varied daytime and nighttime hours in the corridors, lunchrooms, and study lounges of City College, John Jay College, and Borough of Manhattan Community College - all campuses known to have matriculated students of MENASA background. Students from MENASA migrant communities were approached by female interviewers from varied backgrounds connected to MENASA migrant communities and asked about their ancestry. If they met the inclusion criterion, they were asked to participate in a thirty-minute interview about marriage and family in exchange for $\$ 20$. Fewer than half of those approached agreed to participate. The most common reason for declining was that they did not have the time because a class was approaching. We did not have the means to determine whether this answer hid deeper concerns. However, interviewers generally received friendly responses and detected no obvious signs of hostility to the research. In general, we found that respondents were happy for the chance to talk about these issues with researchers who were outside their lives, but shared some of their migrant community experiences.

As is often the case when interviews are conducted with strangers on sensitive topics, field trials revealed that questions about third parties in the respondents' social networks elicited more robust and meaningful responses than those about the person being interviewed. However, some respondents used the open-ended questions about their social networks as an opportunity to discuss their own situations. Many of these first person narratives are used in the qualitative section due to their relative richness, in comparison with the third person narratives that provide the bulk of the data. 
Narratives were identified through a broad qualitative content analysis that drew on 1) a review and analysis of all data from audio recordings; 2) notes taken at intensive debriefing sessions, on site and after interviews; and 3) field notes written by interviewers and research coordinators shortly after completion of multiple interview sessions. A 'bottom-up approach', (Gadd et al., 2012) was employed and attention was given to recurring comments, concerns, and themes: for example, common and uncommon causes for intergenerational conflicts over honour, sexuality, and marital choice. This exploratory technique generated the findings for this study and drew on empirical evidence, incorporating no prior knowledge.

\section{Demographics of the sample}

Students with family from a variety of countries were represented in the sample, but the most prevalent countries represented in the sample were Pakistan, Bangladesh, and India. This mirrors prevalence findings of the UK Forced Marriage Unit (Foreign and Commonwealth Office and Home Office, 2013). Forty-five per cent of the respondents were born in the US and individuals who identified as Muslim were the most prevalent in the sample (75 per cent), followed by Hindu, Pentecostal Christian, Coptic Christian, and Sikh. The majority were traditional college age students, with 69 per cent between eighteen and twenty-one, and another 25 per cent between twenty-two and twenty-five years of age (see Table 1 ).

The earliest reported migration of family members to New York City was 1960, and the latest was 2009. However, the overwhelming majority had attended high school in New York City and spent a significant percentage of their culturally formative years in the US. More than 80 per cent of the sample described themselves as 'not very' or 'somewhat' religious; only 6 per cent were married, though 15 per cent described themselves as engaged.

\section{The scope of the problem}

Our findings indicate that, among respondents, familial conflict over marital choice is extremely common. Seventy per cent of respondents reported knowing at least one couple whose families had objected to their marriage, and a third of the sample knew more than three (see Table 2). This conflict over marital choice also included widespread attempts by parents to arrange marriages that were not wanted by their children. Our sample revealed that 88 per cent of female respondents and 63 per cent of males knew at least one person who had refused to allow parents to arrange a marriage for them (see Table 2). It is not clear the degree to which this represents rejection of the idea of arranged marriages, the actuality of particular proposed matches, or conflicts with parents over 'when' rather than how.

When asked why the people they knew refused to marry (Table 3), 50 per cent of the respondents suggested concerns with the overall process (Americanised and fear of commitment), 19 per cent suggested a problem with the particulars of proposed matches, and 31 per cent provided answers that were ambiguous and difficult to interpret (e.g. 'too young' and 'educational goals'). Respondents described numerous cases of both men and women facing significant pressure from parents and other family members over marital choice. However, women were more conscious of potential problems with 
Table 1 Selected demographics of sample $(N=100)$

\begin{tabular}{|c|c|c|c|c|c|c|c|c|c|c|c|c|c|c|}
\hline \multicolumn{2}{|c|}{ Gender } & \multicolumn{2}{|c|}{ Birthplace } & \multicolumn{5}{|c|}{ Religion } & \multicolumn{3}{|c|}{ Age (years) } & \multicolumn{3}{|c|}{ Marital status } \\
\hline Female & Male & US born & Non-US born & Muslim & Hindu & Penta-costal & Coptic & Sikh & $18-21$ & $22-25$ & $26-37$ & Single & Engaged & Married \\
\hline 59 & 41 & 45 & 55 & 75 & 9 & 7 & 5 & 4 & 69 & 25 & 6 & 79 & 15 & 6 \\
\hline
\end{tabular}


Table 2 Intergenerational conflict over marriage $(\mathrm{N}=100)$

\begin{tabular}{llll}
\hline \hline Interview Question & None & $1-2$ & 3 or more \\
\hline $\begin{array}{l}\text { Number of couples you know whose } \\
\text { family objected to their marriage }\end{array}$ & 30 & 38 & 32 \\
$\begin{array}{c}\text { Number of people you know who did not } \\
\text { want to marry, but did }\end{array}$ & 16 & 53 & 31 \\
$\begin{array}{c}\text { Number of people you know who refused } \\
\text { an arranged marriage (Women) }\end{array}$ & 12 & 52 & 36 \\
$\begin{array}{c}\text { Number of people you know who refused } \\
\text { an arranged marriage (Men) }\end{array}$ & 37 & 37 & 26 \\
\hline \hline
\end{tabular}

Table 3 Why do people refuse marriages?

$(\mathrm{N}=100)$

\begin{tabular}{lc}
\hline \hline Reason cited & $\mathrm{N}=$ \\
\hline Commitment & 31 \\
Americanised & 19 \\
Education/Career & 17 \\
Bad Match & 19 \\
Too Young & 14 \\
\hline \hline
\end{tabular}

arranged marriage, as demonstrated by both the greater number who knew of at least one person who had refused an arranged marriage and the smaller percentage who viewed arranged marriage as 'better' (see Table 2). This may reflect the greater vulnerability of young women attempting to claim agency and control over their sexual, marital, and reproductive lives.

Respondents gave conflicting and ambivalent answers around issues connected to dating and sexual propriety. For example, nearly half reported that it is useful to live together before marriage, but over two thirds reported it as 'socially unacceptable', and 100 per cent said that their parents would not allow it. Finally, 84 per cent indicated that they knew somebody who had not wanted to be married (see Table 2), but had done so anyway. This suggests that intergenerational conflict over marital choice is a significant issue for young adults from MENASA migrant families, and may include what has been defined, in the European context, as forced marriage.

\section{Marriage and honour conflict in New York City}

The following qualitative data are presented to document the familial conflicts over marital choice described by respondents. We intentionally avoided asking respondents if their parents had tried to pressure them into a marriage, due to the defensive responses we had encountered in field trials of the interview instrument. The term forced marriage often inspired respondents to be defensive perhaps because using the term restricted the interviewee's agency to conceptualise and convey their experiences. However, the 
question 'Do you know anybody who refused to get married?' yielded a common first response, 'Yes, me.' Sometimes, the respondent backed away from this first response and indicated it was an exaggeration. Other times respondents described nearly succumbing to an unwanted marriage. In two cases (see first section, below) this question elicited narratives about the respondent's own marriage.

Of those respondents who said that they knew people who had 'refused to get married,' when asked to 'tell us about them,' respondents generally described outcomes in which the 'girl ran away', rather than ones in which violence occurred. Honour and endogamy were widely described as important to parental decisions about marriage and numerous examples were given of children struggling to balance lives in the society in which they were raised with ties to sending countries and their marital customs.

In the following section we recount examples of marriages that were made despite the objections of one of the principals. In the subsequent section we recount examples of resistance and concern around potential violence that may be the backdrop to some family decisions.

\section{Marital conflict and obedience}

Jemma ${ }^{2}$, a Bangladeshi woman from the Bronx, one of four married respondents, told her story of agreeing to a marriage made by her parents. Returning home one night from her job as a cashier, her father surprised her with the news that she was getting married that summer to a young Bangladeshi man that her father 'respected and admired.' The arrangements were already made and a date set for the wedding. Jemma said that at the time, she was completely distraught and resented her father for not discussing the marriage arrangement with her. She 'cried for days and weeks,' but was reassured by her mother, aunts, and other female family members that there was no need to worry because all of their marriages were arranged and had turned out well, and hers would too.

Jemma decided that she would marry because she did not want to go against her father's will or 'build a reputation as the immodest daughter' in her family and community. Today, Jemma is raising a daughter with the man that her father selected and reports to be very happy. She said her husband is everything she could ever ask for in a partner, that her father was right, and she is glad she 'went along with his plans.'

A young Bangladeshi student, Fatima, reported that her father arranged her marriage before she started college. Although a wedding date was not confirmed, she was expected to marry a distant cousin after completing her undergraduate studies. In her senior year, Fatima's father died from cancer. Soon after, Fatima's mother asked whether she was ready for the marriage that her father had arranged. Fatima replied that she wanted to complete her undergraduate studies before thinking about marriage.

Her mother was ambivalent, but supportive of her decision. She warned that if Fatima did not want to get married, she should decide immediately so that the cousin's family could be notified and her family could 'save face'. Her mother added that in Bangladesh, 'your father's word is the family's honor,' and if her decisions were not parallel to her father's promises, then the family could no longer 'show face' in the community and her father would not be able to rest in peace. Despite the offer from her mother to cancel the arrangement, Fatima said that she felt emotionally and mentally pressured to follow through on her dead father's arrangements. A few hours after the conversation, she told her mother that she would get married and expects to be married shortly after graduation. 
Zalina, also Bangladeshi and Muslim, reported that during her freshman year, her parents caught her and her boyfriend together in public. Zalina's boyfriend was also Muslim and Bangladeshi, but her parents did not permit her to date and demanded that she stop dating her boyfriend. Soon afterwards they took Zalina to Bangladesh and arranged a marriage for her before her behaviour damaged the family's reputation. Zalina complied with their demands; she broke off her relationship with her boyfriend, moved to Bangladesh, married the young man that her parents selected, got pregnant shortly after, and moved back to the US to have the baby though her husband still lives in Bangladesh. She is now continuing college, raising a daughter by herself, and finds it 'extremely difficult to balance the life of a mother, wife, and student.' Zalina added that 'married life is miserable' and that she 'wouldn't wish it upon [her] worst enemy.'

\section{Marital conflict and resistance}

Over the course of the interviews, strategies to sabotage an unwanted arranged marriage without open conflict became apparent. Our view into these strategies was sharpened in an interview with Sammy, a twenty-one-year-old who was born in Yemen, but who moved to NYC in early childhood with his mother to join their father who had come in 1979. Sammy, self-described as 'highly Americanized', gave no hint at the conflict this caused at home until we asked him whether it was 'useful or desirable to live together before getting married.' Sammy said that he was currently engaged and facing this problem: he had no idea what his future wife looked like or anything about her. He did not want to marry, but did not know how to avoid his family's plans for him.

However, Sammy told us about a young woman he knew whose story held some hope for him. Mona, born in the US of Yemeni parents, had her marriage arranged by her family to a man from Yemen, Zac. She never voiced her opposition to the marriage because she 'didn't want to make her family look bad.' Rather than confront the family's plans and risk a backlash, she was 'obedient', accepted her fate, and got married. However, Sammy said that she never got pregnant and she encouraged friends to 'spread rumors about her in the Yemeni community that she was too Americanized' to be a suitable partner. Sammy reported that the marriage was 'dissolved' within two years. Mona, who had managed to satisfy her family's demand that she get married while gaining her freedom in the process, provided Sammy hope that there was a way out for him.

Later, by chance, we interviewed Mona - the woman whose experience was described by Sammy. When asked about her marriage, she said that she was 'confused and didn't want to get married,' but was 'talked into it by her mother.' After the Niqa was signed, the couple was 'married in the eyes of the families,' but they did not live together, a common arrangement for newlyweds. Over the next few months, however, Zac began to call Mona on the phone and occasionally visited her at her parents' house, but she was not responsive to his efforts to develop a relationship and often would not take his calls or allow him to visit.

Eventually, Mona asked Zac for a divorce and his family agreed, but demanded the money that had changed hands when the agreement was settled be returned - by the now estranged father. She and her mother had lost enough honour to facilitate the divorce without ongoing conflict or violence. However, as many of our male respondents pointed out, such strategies for avoiding a parental marital choice would not likely work for men, 
for whom sexual propriety and 'over Americanization' did not present blemishes to the family honour.

A twenty-one-year-old female respondent who had been born in Pakistan, but grew up in the US, described a situation in which her parents had threated mutual suicide if her brother did not accept a marriage they had arranged with a family in Pakistan. Fearing the potential for conflict, he had travelled to Pakistan to marry, but upon returning to the US took a job in Seattle, refused his wife's phone calls and did nothing to sponsor her US residence papers. She began calling his parents, who again threatened to kill themselves if he did not bring his wife to the US and consummate the marriage. He finally 'stood up for himself and divorced her'. His sister feared that her parents were planning the same thing for her and that she might not be able to escape as her brother had. Her hope was that he would protect her, despite living three thousand miles away.

We encountered one situation in which the typical conflict over arranged marriages was inverted with a child pressuring her parents to arrange a marriage. Jasmine was a twenty-one-year-old woman born in the US to liberal and educated Palestinian parents who had come to the US in the 1980s to finish their education - the mother high school and the father college. Her parents prided themselves on being cosmopolitan and liberal. They were strongly opposed to arranged marriages and had raised their daughter with the expectation that she would wait until she had finished school to marry and start a life of her own.

Jasmine, lacking confidence about 'boys' and uneasy with dating, pressured her parents to arrange a marriage for her, as more traditional neighbours had done for their daughters. Her parents had little familiarity with marriage markets and opposed her desires. In discussing her preference for an arranged marriage she invoked the problems of a twenty-two-year-old first cousin who had eloped with an unemployed African American man. When the relationship became a topic of neighbourhood gossip, Jasmine's aunt and uncle started telling people that their daughter had been kidnapped. When the daughter finally returned home to claim her possessions, her aunt and uncle had her held under lock and key for three days. The girl finally called the police, who apparently refused to intervene in 'a problem of traditional Arab parents.'

\section{Conclusion: unease, ambivalence, conflict, and pride}

In our sample of 100 City University of New York students, we spoke with individuals who are likely to be among the more privileged and acculturated youth from MENASA families. The overwhelming majority knew individuals who they believed had made marriages they did not want. Several respondents presented narratives in which full consent by both principals to a marriage was questionable and nearly all had examples of everyday family conflicts over behaviour, values, and cultural affiliation.

Respondents described a widespread pattern of conflict and ambivalence over honour and culture for themselves and their social networks. Most of it involved bickering over not atypical parent/child concerns such as with whom neighbours saw them walking, what they were wearing, how they addressed a relative, or what they did after school. Many of the bicultural actors that we interviewed were ambivalent about their position between the two cultures, saying that they wanted to be 'Americanized', but describing concessions to cultural norms that they valued and appreciated, but also viewed as alien to their upbringing in New York City. 
This ambivalence often took the form of what Michael Herzfeld (2004) has described as 'cultural intimacy', or 'the recognition of those aspects of a cultural identity that are considered a source of external embarrassment but that nevertheless provide insiders with their assurance of common sociality.' Several times, researchers shared informal joking sessions after an interview about what it would take to make their own relatives become violent. Such joking seemed to suggest an unease and ambivalence about the limits of being 'Americanized', as well as affection for and identification with older family members, whom respondents described as facing similar dilemmas involving ambivalence, cultural confusion, and inter-culturality. Parents were typically described as valuing their children's success at integrating into the receiving society, but often seemed to live in fear of the judgments of relatives 'back home' and neighbours within their migrant enclave, leading to often contradictory actions and judgments in face of their children's choices. We conclude, from this research that there is indeed a high probability that coercive marital situations are a problem for some young people in the US, especially those who live deeper in immigrant enclaves. However, in considering the question of importing European-style forced marriage laws, practices and institutions, it is worth noting some socio-political differences in the US context.

It has been argued that the lack of a comprehensive pact of citizenship between individuals and the state makes the nuclear family more important in the US than in most other Western democracies (Coontz, 2016). Many young people obtain their healthcare from parents, who receive benefits through their employment: children can receive parental healthcare employment benefits until they are twenty-seven years old. The vast majority of employment held by youth is paid at or near the minimum wage and does not include health insurance, leaving millions of juridical adults in their early twenties in a near childlike state of economic dependence. More importantly for MENASA youth seeking independence from parents, tertiary education yields a greater economic return over the course of a lifetime in the US than in any Western European country (Corak, 2013), but there is less government support for prohibitive university fees (OECD, 2017).

Most of our respondents depended on their parents for financial help with their college education and needed copies of their parents' tax returns to gain need-based government financial aid and guaranteed loans. The unsubsidised minimum wage in the United States is not meant to be sufficient for independent adult life and the twenty-sixweek government unemployment relief program is only available to a tiny percentage of the population under twenty-four years old. These are only a few examples of the structural privileging of the nuclear family in the United States. This situation arguably gives young people, especially females, fewer resources for negotiating with their families over marital choice, education, employment, and other life choices, and may reduce the overall expectations that resistance to parental marriage arrangements is possible or desirable.

We hypothesise that the greater sense of a direct individual relationship of citizens with the state that is predominant in most European countries may facilitate forced marriage policies in a way that would be less effective in the US. For European migrant youth who are fully adult (or soon to be) citizens with their own direct relationship with the welfare state there may be a greater likelihood that they will more readily define their conflicts with older relatives over marital choice as 'forced marriage', and demand the right to consent that is due citizens. In such circumstances there is more of an expectation 
that the state exists to protect mature minors and young adults from the demands of migrant parents and their communities. This may explain some of the success of British and Dutch forced marriage law enforcement efforts ${ }^{3}$. Such youth may seek support from civil society organisations and government agencies where US based MENASA youth may be more resigned to dependency and compromise.

However, it may be that non-MENASA American youth also face greater pressures and constraints in their marital choices than their counterparts in other Western nations with more robust welfare states. The higher marriage and divorce rates in the US may be to an extent a reflection of these greater pressures and constraints. For this reason, we believe that further research into the topic in the US might be most effective if it avoids the dichotomy between forced and chosen marriage that has characterised the European approach and some of the preliminary US research.

In the US, where rewards for marriage are structurally embedded in both social processes and financial and legal codes to a greater degree than in most European contexts, we would argue, instead, for inquiries into the conditions under which young people choose their sexually based kinship. In this highly preliminary inquiry we found that the term 'forced marriage' was generally taken by our respondents as invidious and created intense defensiveness in those being studied, by predefining their experiences as incomparable to and worse than those of more mainstream Americans. However, we found that given a less challenging approach, young people from MENASA backgrounds were very enthusiastic about discussing the conflicts and contradictions they faced in dealing with dating, marital choice, and family values.

Similarly, in advocating for new laws and institutions designed to protect young people from unwanted matrimony, it is our sense, using data drawn from questionnaires, observations, and social engagement with respondents before, during and after the interviews, that even in the best of circumstances the tendency towards invidious cultural comparison embedded in terms like forced marriage and honour violence does not create the sense of trust, belonging or empowerment that we believe is the precondition for addressing intergenerational conflict over marriage and sexuality. In fact, our research developed in an environment that might well be described as the best of circumstances. Few of our respondents had ever heard the term forced marriage; none of them were familiar with the intense cultural conflicts, political debates, and accusations of racism that have characterised the European discussions of the issue; none of them had heard of members of their community being arrested for such cultural crimes; and they were being interviewed by female CUNY students from similar MENASA migrant backgrounds.

Despite something of a blank slate, discussions of the term forced marriage that invoked some of the connected European tropes made most respondents defensive and even angry at what they perceived as cultural invidiousness. Given the recent elections that brought Donald Trump to the White House, concerns about immigration, particularly from MENASA countries, and the current climate of intensified war in the Middle East, North Africa and South Asia, it is difficult to imagine that European style anti-forced marriage policy projects being pursued by non-profits and civil society advocates represent the best approach at this particular historical juncture.

In a country where young adults have few of the political or economic rights that European youth typically count upon, European definitions and laws that are heavily focused on criminal justice intervention and comparative cultural judgment may well reduce the space for marital choice among MENASA youth, rather than increase it. 
The UK Forced Marriage Unit has documented extreme cases of intergenerational marital conflict among MENASA families and we have no doubt that scenarios involving serious violence, terrifying threats and outright kidnapping also exist in the United States. However, our research suggests that such cases are probably not the norm, and may be so prominent in public service campaigns due in part to what Cojocaru (2016) refers to as 'secondary exploitation', or the use of women's victimhood for valorising the work and fundraising of non-profits.

Advocacy organisations have promoted the idea of young women putting spoons and forks into their underwear to set off airport metal detectors and enable police to save them from forced marriages in distant countries, but this study suggests that such criminal justice focused approaches may be unrealistic, unhelpful, and sensationalist. Our data suggest that the problems MENASA youth face around intergenerational conflict over sexuality and marriage may be more subtle and complicated. Right or wrong, probably all the youth we met would interpret an attempt, in the current sociopolitical climate, to create European style forced marriage laws and institutions as an attack on themselves, their families, and their culture.

However, we believe there are many opportunities to work towards promoting the autonomy, sense of belonging, and individual agency in young people from migrant families that is necessary to prevent forced marriage. More specific legal statutes and greater involvement of law enforcement do not seem to be the place to begin. More knowledge of how ordinary MENASA youth experience and understand intergenerational conflicts over marriage and sexuality is needed. Much of the research that has been implemented to date has sought to study victimisation, rather than the quotidian conflicts that are experienced by the majority of our respondents.

Given that our sample was obtained through random intercept in public spaces and that 84 per cent of respondents were willing to describe situations in which individuals in their social networks had married despite not wanting to, the research demonstrates that, with or without an explicit forced marriage policy from the US government, significant opportunities exist for extensive research on, and concerned social service and educational interventions for, supporting MENASA youth, marital choice, and consent. Such a holistic, empirical and in situ effort to understand the source of these conflicts where they occur, rather than after they have reached the point of crisis, would seem to be the necessary precondition for assessing the utility of importing seemingly divisive and culturally invidious European laws and definitions to an American socio-political context.

\section{Acknowledgement}

We would like to acknowledge the following people for their support in research design, implementation and analysis: Alana Henninger, Engy Hanna, Lisa Robbins-Stathas, Julia Sandler, and the AHA Foundation.

\section{Notes}

1 In the US, parental or judicial consent is needed for a person under the age of eighteen to wed in all but two states (Le Strat et al., 2011).

2 All names have been changed to protect respondents' privacy.

3 However, Begum (2016) suggests that people affected by forced marriage in the US and UK are not typically comfortable with punitive legal responses and prefer a non-criminal approach. 


\section{References}

Abu-Lughod, L. (2011) 'Seductions of the "honor crime"', Differences, 22, 1, 17-63.

AHA (2014) The AHA Foundation Third Annual Conference on Honor Violence, Forced Marriage, and Female Genital Mutilation, https://www.theahafoundation.org/the-aha-foundation $\%$ E2\% $80 \%$ A8-third-annual-conference-on-honor-violence-forced-marriage-and-female-genital-mutilation/ [accessed 31.08. 2017].

Ahmetbeyzade, C. (2008) 'Gendering necropolitics: The juridical-political sociality of honor killings in Turkey', Journal of Human Rights, 7, 187-206.

Alanen, J. (2011) 'Table: Forced marriage laws of the U.S. states and territories', http:// globaljusticeinitiative.wordpress.com/gji-e-library/library-2/ [accessed 19.04.2013].

Anitha, S. and Gill, A. (2009) 'Coercion, consent and the forced marriage debate in the UK', Feminist Legal Studies, 17, 2, 165-84.

Baer, H.A. (1988) Recreating Utopia in the Desert: A Sectarian Challenge to Modern Mormonism, SUNY Press.

Balán, J. (1996) 'Stealing a bride: marriage customs, gender roles, and fertility transition in two peasant communities in Bolivia', Health Transition Review, 69-87.

Begum, P. (2016) 'Should 'forced marriage' be criminalised?', Howard League for Penal Reform, London: UK.

Bennhold, K. (2013) 'A Muslim prosecutor in Britain, fighting forced marriages and honor crimes', New York Times, 27 September.

Caroll, L. (1998) Arranged Marriages: Law, Custom, and the Muslim Girl in the U.K., Report, Women Living Under Muslim Laws Dossier, Senegal, Pakistan, UK, July.

Chantler, K. (2012) 'Recognition of and intervention in forced marriage as a form of violence against women', Trauma, Violence, and Abuse, 13, 3, 176-83.

Chantler, K., Gangoli, G. and Hester, M. (2009) Forced marriage in the UK: religious, cultural, economic or state violence?' Critical Social Policy, 29, 4, 587-612.

Clinton, H. (2011) 'The fight against child marriage', Glamour Magazine, 8 February.

Cojocaru, C. (2016) 'My experience is mine to tell: challenging the abolitionist victimhood framework', Anti-Trafficking Review, 7, 12-38.

Coontz, S. (2016) The Way we Never Were: American Families and the Nostalgia Trap, Hachette UK.

Corak, M. (2013) 'Income equality, equality of opportunity, and intergenerational mobility', Journal of Economic Perspectives, 27, 3, 79-102.

Epstein, R., Pandit, M. and Thakar, M. (2013) 'How love emerges in arranged marriages: two cross-cultural studies', Journal of Comparative and Family Studies, 44, 3, 341-60.

Foner, N. (1997) 'The immigrant family: cultural legacies and cultural changes', International Migration Review, 31, 4, 961-74.

Forced Marriage Unit (2014) Statistics January to December 2014, https://www.gov.uk/government/ uploads/system/uploads/attachment_data/file/412667/FMU_Stats_2014.pdf [accessed 05.10.2017].

Foreign and Commonwealth Office and Home Office (2013) Forced Marriage: Information and Practice Guidelines for Professionals Protecting, Advising and Supporting Victims, www.gov.uk/ forced-marriage\# overview [accessed 19.04.2013].

Foreign and Commonwealth Office, Scottish Executive, and Home Office (2006) Forced Marriage: A Wrong not a Right, Report, Forced Marriage Unit, UK, June.

Gadd, D., Karstedt, S. and Messner, S.F. (2012) The SAGE Handbook of Criminological Research Methods, London, UK: Sage Publications.

Gangoli, G., Razak, A. and McCarry, M. (2006) Forced Marriage and Domestic Violence among South Asian Communities in North East England, Report, University of Bristol and Northern Rock Foundation, UK, June. 
Ghimire, D. J., Axinn, W. J., Yabiku, S. T. and Thornton, A. (2006) 'Social change, premarital non-family experiences and spouse choice in an arranged marriage society', American Journal of Sociology, 111, 4, 1181-218.

Gill, A. K. and Anitha, S. (2011) 'The social construction of forced marriage and its 'victim' in media coverage and crime policy discourses', in A. K. Gill and A. Sundari (eds.), Forced Marriage: Introducing a Social Justice and Human Rights Perspective, London: Zed Books, London, 112-34.

Girlsnotbrides (2013) Child Marriage 'a Fundamental Threat to Human Rights' - Barack Obama, http://www.girlsnotbrides.org/child-marriage-a-fundamental-threat-to-human-rights-barack-obama/ [accessed 05.10.2017].

Goluboff, S. L. (2001) 'The savage in the Jew: race, class, and nation in post-soviet Moscow', Identities Global Studies in Culture and Power, 8, 2, 283-312.

Herzfeld, M. (2004) Cultural Intimacy: Social Poetics in the Nation-State, London: Routledge.

Hester, M., Chantler, K., Gangoli, G., Devgon, J., Sharma, S. and Singleton, A. (2007) Forced Marriage: The Risk Factors and the Effect of Raising the Minimum Age for a Sponsor, and of Leave to Enter the UK as a Spouse or Fiancé(e), Report, University of Bristol, UK, August.

Home Office (2000) A Choice by Right: The Report of the Working Group on Forced Marriage, Report, London, June.

Hossain, S. and Turner, S. (2002) Abduction for Forced Marriage: Rights and Remedies in Bangladesh and Pakistan, Report, University of London School of Oriental and African Studies, UK.

Hvilshøj, R. (2006) 'Speech by Danish Minister of Integration', Politiken, 24 January, section 2, 6 [translation, M. Hester].

Jacoby, H. G. and Mansuri, G. (2010) 'Watta Satta: bride exchange and women's welfare in rural Pakistan', American Economic Review, 100, 4, 1804-25.

Jejeebhoy, S. J. and Sathar, Z. A. (2001) 'Women's autonomy in India and Pakistan: the influence of religion and region', Population and Development Review, 27, 4, 687-712.

Le Strat, Y., Dubertret, C. and Le Foll, B. (2011) 'Child marriage in the United States and its association with mental health in women', Pediatrics, 128, 524-30.

Mair, L. P. (2013) African Marriage and Social Change, Routledge.

Oprea, A. (2005) 'The arranged marriage of Ana Maria Cioaba, intra-community oppression and Romani feminist ideals: transcending the "primitive culture" argument', European Journal of Women's Studies, $12,2,133-48$.

Organisation for Economic Co-operation and Development (2017) Education at a Glance: OECD Indicators 2017, OECD.

Phillips, A. and Dustin, M. (2004) 'UK initiatives on forced marriage: regulation, dialogue and exit', Political Studies, 52, 3, 531-51.

Qin, D. B. (2006) 'The role of gender in immigrant children's educational adaptation', Current Issues in Comparative Education, 9, 1, 8-19.

Razak, S. H. (2004) 'Imperilled Muslim women, dangerous Muslim men and civilised Europeans: legal and social responses to forced marriages', Feminist Legal Studies, 12, 2, 129-74.

Robbins, L. (2009) 'Upstate man charged with beheading his estranged wife, New York Times, Feb 17.

Roy, D. (2011) An Introduction to Forced Marriage in the South Asian Community in the United States, Report, Occasional Paper No. 9 for Manavi, New Brunswick, NJ, USA.

Sarroub, L. K. (2001) 'The sojourner experience of Yemeni American high school students: an ethnographic portrait, Harvard Educational Review, 71, 3, 390-415.

Sauti Yetu Center for African Women and Families (2012) A Closer Look at Forced and Early Marriage in African Immigrant Communities in New York City, Report, Occasional Report Vol. 3, New York, USA.

Shalhoub-Kevorkian, N. (2004) 'Racism, militarism, and policing: police reactions to violence against Palestinian women in Israel, Social Identities, 10, 2, 171-93. 
Siddiqi, D. (2005) 'Of consent and contradiction: forced marriages in Bangladesh', in S. Hossain and L. Welchman (eds.), 'Honour': Crimes, Paradigms and Violence Against Women, New York: Zed Books, 282-307.

Sikder, S. (2013) New Evidence on Child Marriage Prevention in Ethiopia, http://blog.usaid.gov/2013/ 11/new-evidence-on-child-marriage-prevention-in-ethiopia/ [accessed 05.10.2017].

Smart, C. and Shipman, B. (2004) 'Visions in monochrome: families, marriage and the individualization thesis', The British Journal of Sociology, 55, 4, 491-509.

Sri, V. and Raja, D. (2013) Voices from the Frontline: Addressing Forced Marriage within the United States, Report, Gangashakti, USA.

Stollavistskaia, A. and McElroy, B. (2005) Divorced from Reality: The True Impact of Denmark's 24 Year-Old Rule, http://www.humanityinaction.org/knowledgebase/235-divorced-fromreality-the-true-impact-of-denmark-s-24-year-old-rule [accessed 19.04. 2013].

Tahirih Justice Center (2011) Forced Marriage in Immigrant Communities in the United States, Report, Falls Church, VA, USA: September.

Toor, S. (2012) 'Imperialist feminism redux', Dialectical Anthropology, 36, 147-60.

Twamley, K. (2013) 'The globalisation of love? Examining narratives of intimacy and marriage among middle-class Gujarati Indians in the UK and India', Families, Relationships and Societies, 2, 2, 26783.

United States Census Bureau (2010) United States 2010 Census, www.census.gov [accessed 05.10.2017].

United States Department of State (2005) Foregn Affairs Manual Volume 7, Consular Affairs, http://www.state.gov/documents/organization/86757.pdf [accessed 05.10.2017].

United States House of Representatives (2014) Committee Reports 113th Congress (2013-2014), House Report, 113-71.

Volpp, L. (2000) 'Blaming culture for bad behaviour', Yale Journal of Law and the Humanities, 12, 1, 89-116.

Wierucka, A. (2013) 'Traditional Huaorani culture and acculturation', in Huaorani of the Western Snippet, US: Palgrave Macmillan, 69-111.

Wilson, A. (2007) 'The forced marriage debate and the British state', Race and Class, 49, 1, 25-38.

Xiaohe, X. and Whyte, M. K. (1990) 'Love matches and arranged marriages: a Chinese replication', Journal of Marriage and the Family, 52, 3, 709-22.

Yost, J. (1994) 'Waorani', in J. Wilbert (ed.), Encyclopedia of World Cultures, New York: G. K. Hall, 351-4.

Zaidi, A. U. and Shuraydi, M. (2002) 'Perceptions of arranged marriages by young Pakistani Muslim women living in a Western society', Journal of Comparative Family Studies, 33, 4, 495-514. 